University of Nebraska - Lincoln

DigitalCommons@University of Nebraska - Lincoln

Faculty Publications in the Biological Sciences

Papers in the Biological Sciences

$11-2005$

\title{
Rapid Senescence in Pacific Salmon
}

\author{
Yolanda E. Morbey \\ University of Toronto \\ Chad Brassil \\ University of Nebraska - Lincoln, cbrassil@unl.edu \\ Andrew P. Hendry \\ McGill University
}

Follow this and additional works at: https://digitalcommons.unl.edu/bioscifacpub

Part of the Biology Commons

Morbey, Yolanda E.; Brassil, Chad; and Hendry, Andrew P., "Rapid Senescence in Pacific Salmon" (2005). Faculty Publications in the Biological Sciences. 314.

https://digitalcommons.unl.edu/bioscifacpub/314

This Article is brought to you for free and open access by the Papers in the Biological Sciences at DigitalCommons@University of Nebraska - Lincoln. It has been accepted for inclusion in Faculty Publications in the Biological Sciences by an authorized administrator of DigitalCommons@University of Nebraska - Lincoln. 


\title{
Rapid Senescence in Pacific Salmon
}

\author{
Yolanda E. Morbey, ${ }^{1, *}$ Chad E. Brassil ${ }^{2, \dagger}$ and Andrew P. Hendry ${ }^{3, \neq}$
}

1. Department of Zoology, Ramsay Wright Zoological Laboratories, University of Toronto, 25 Harbord Street, Toronto, Ontario M5S 3G5, Canada;

2. W. K. Kellogg Biological Station, Michigan State University, Hickory Corners, Michigan 49060;

3. Redpath Museum and Department of Biology, McGill

University, 859 Sherbrooke Street West, Montréal, Québec H3A

2K6, Canada

Submitted October 27, 2004; Accepted July 19, 2005;

Electronically published September 9, 2005

\begin{abstract}
Any useful evolutionary theory of senescence must be able to explain variation within and among natural populations and species. This requires a careful characterization of age-specific mortality rates in nature as well as the intrinsic and extrinsic factors that influence these rates. We perform this task for two populations of semelparous Pacific salmon. During the breeding season, estimated daily mortality rates increased from 0 to $0.2-0.5$ (depending on the year) over the course of several weeks. Early-arriving individuals had a later onset and/or a lower rate of senescence in each breeding season, consistent with adaptive expectations based on temporal variation in selection. Interannual variation in senescence was large, in part because of extrinsic factors (e.g., water temperature). Predation rates were higher in Pick Creek sockeye salmon (anadromous Oncorhynchus nerka) than in Meadow Creek kokanee (nonanadromous O. nerka), but in contrast to evolutionary theory, senescence was not more rapid in the former. Interannual variation may have obscured interpopulation divergence in senescence. Pacific salmon are a promising system for further studies on the physiological, evolutionary, and genetic bases of senescence. In particular, we encourage further research to disentangle the relative importance of adaptive and nonadaptive variation in senescence.
\end{abstract}

Keywords: senescence, Oncorhynchus, survival analysis, adaptive variation.

\footnotetext{
* Present address: Aquatic Research and Development Section, Ontario Ministry of Natural Resources, 1450 7th Avenue East, Owen Sound, Ontario N4K 2Z1, Canada; e-mail: yolanda.morbey@mnr.gov.on.ca.

† E-mail: brassilc@kbs.msu.edu.

₹ E-mail: andrew.hendry@mcgill.ca.
}

Am. Nat. 2005. Vol. 166, pp. 556-568. (C) 2005 by The University of Chicago. 0003-0147/2005/16605-40706\$15.00. All rights reserved.
A focal point in the study of life histories has been the evolution of senescence, a decrease in fertility and/or survival with age (Williams 1957; Hamilton 1966; Roff 1992; Stearns 1992; Roff 2002). A major unifying goal of this work has been to explain both the proximate and the ultimate causes underlying the tremendous diversity in senescence observed within and among species (Promislow 1991; Rose 1991; Ricklefs 1998; Reznick et al. 2002). Recent research has focused on several fundamental questions within this overall goal. First, is senescence caused by homologous processes in divergent taxa (Partridge 2001; Partridge and Gems 2002)? Second, does senescence occur because of mutation accumulation or antagonistic pleiotropy (Dudycha and Tessier 1999; Partridge 2001; Hughes et al. 2002; Partridge and Gems 2002)? Third, what is the role of extrinsic mortality in causing adaptive variation within and among populations and species (Abrams 1993; Keller and Genoud 1997; Ricklefs 1998; Dudycha and Tessier 1999; Williams and Day 2003; Bryant and Reznick 2004; Reznick et al. 2004)?

Much of the evolutionary research on senescence has focused on Drosophila, which are particularly conducive to laboratory experiments and have well-characterized genetics. And yet a comprehensive understanding of how and why senescence evolves requires complementary research on other taxa and in natural populations. Natural populations provide the opportunity to assess the relative importance of intrinsic (i.e., physiological) versus extrinsic mortality in shaping adaptive and nonadaptive patterns in senescence within and among species. For example, adaptive variation in senescence has been examined in red deer (Carranza et al. 2004), opossums (Austad 1993), guppies (Bryant and Reznick 2004; Reznick et al. 2004), grasshoppers (Tatar et al. 1997), Daphnia (Dudycha and Tessier 1999), and antler flies (Bonduriansky and Brassil 2005).

Another recently emerging system for studying the evolution of senescence is Pacific salmon (Oncorhynchus spp.), in which most species are obligatorily semelparous. Pacific salmon have been the subject of much research on the physiological mechanisms of senescence, but only recently have they been used to inform evolutionary theories of senescence (Morbey and Ydenberg 2003; Hendry et al. 2004; Morbey and Abrams 2004). These studies focused 
on a commonly observed seasonal pattern of senescence and why it might be adaptive but did not fully assess the factors contributing to variation in age-specific mortality rates. For the study of senescence to advance further in this system, an important next step is to obtain a detailed picture of age-specific mortality rates in nature and to determine how they are affected by intrinsic and extrinsic factors. This article forwards this goal.

\section{Senescence in Pacific Salmon}

Rapid senescence, which is taxonomically widespread in plants and animals, appears to be a consequence of extreme investment in reproduction and is often associated with the cessation of feeding, weight loss, atrophy of digestive organs, impaired immune function, and elevated neuroendocrine function (Finch 1990). Semelparous $\mathrm{Pa}$ cific salmon are a particularly well-known example of rapid and irreversible senescence associated with reproduction (Williams 1966, pp. 174-175; Finch 1990, pp. 8392). Indeed, senescence in salmon is so rapid that individuals seemingly in the peak of health and vigor when they start breeding undergo precipitous physical decline and die only weeks later (McPhee and Quinn 1998; Hendry et al. 1999, 2001, 2004; Morbey and Ydenberg 2003). This senescence appears to be primarily a manifestation of stress and starvation regulated by neuroendocrine hormones (reviews in Dickhoff 1989; Finch 1990; Stein-Behrens and Sapolsky 1992; Barry et al. 2001; Maldonado et al. 2002). Starvation, in particular, appears paramount because $\mathrm{Pa}$ cific salmon do not feed during reproduction and instead rely on the catabolism of fat and muscle protein to fuel breeding activity. As a result, Pacific salmon lose 40\%$80 \%$ (population averages) of their stored energy during the reproductive period (Gilhousen 1980; Brett 1995; Hendry and Berg 1999). Elevated corticosteroids (i.e., cortisol) are associated with this process because they regulate protein metabolism and gluconeogenesis, but they also depress natural immune defense mechanisms (Finch 1990; Mommsen et al. 1999; Carruth et al. 2000). Another important mechanism of senescence appears to be oxidative stress (Sawada et al. 1993; Golden et al. 2002; Sohal et al. 2002).

This strong background on the physiological basis of senescence in Pacific salmon sets the stage for evolutionary studies seeking to explain variation within and among populations and species. Several aspects of Pacific salmon biology aid these endeavors. First, their use of stored energy for reproduction simplifies the underlying trade-off between energy invested in survival and in reproduction (e.g., Boggs 1997a, 1997b). Second, much is known about their mating system, behavior, and competitive interactions (review in Groot and Margolis 1991). Third, different breeding groups experience dramatically different ecological environments (Groot and Margolis 1991), which should impose a diversity of selective pressures acting at different reproductive ages. Fourth, large numbers of individuals can be tracked in ecologically relevant settings to determine mortality rates and cause of death.

Taking advantage of these properties, we characterize the functional form of age-specific mortality in natural salmon populations. We perform this analysis for two very different sockeye salmon (Oncorhynchus nerka) populations. In doing so, we conclusively demonstrate the acceleration of mortality that occurs before death. We then examine how the form of this accelerated senescence varies among years, sexes, and populations. These comparisons allow us to determine whether several extrinsic and intrinsic factors influence senescence. We complement these analyses of mortality with a consideration of senescence manifested as declining reproductive rate.

\section{Methods}

We examined age-specific mortality in two populations of Oncorhyncus nerka: anadromous (oceangoing) sockeye salmon from Pick Creek, Alaska, and nonanadromous (freshwater-resident) kokanee from the Meadow Creek spawning channel, British Columbia. These study systems and their O. nerka populations have been described at length in previous work (Pick Creek: Mathisen 1962; Hendry and Berg 1999; Hendry et al. 1999, 2001, 2004; Quinn et al. 2001a; Meadow Creek: Vernon 1957; Foote 1988, 1990; Morbey 2002, 2003; Morbey and Ydenberg 2003).

For Pick Creek, we captured male and female sockeye salmon with seine nets where the creek enters Lake Nerka. All fish were individually marked with Peterson disk tags (Floy Tag, Seattle, WA), sexed, measured for length (middle of the eye to end of the hypural plate), and released at their capture site. They then entered Pick Creek according to their own schedule. The entire creek was surveyed daily to determine the location, breeding behavior, and the date and cause of death for each marked individual. Fewer than $1 \%$ of the tagged fish could not be identified on a given day. Otoliths (ear stones) were removed from recovered carcasses and used to determine ocean age and the relationship between body length and ocean age. These relationships were then also used to determine the ocean age of fish who were not recovered at death (see Hendry et al. 1999 for details).

In Meadow Creek, hundreds of thousands of kokanee arrived at an enumeration fence downstream of the breeding channel, making it difficult to estimate their natural arrival schedule. Instead, we used a dip net to capture a sample (48 males and 48 females) of newly arriving fish over a 21-day period. Each fish was individually marked 
with a Peterson disk tag attached through the dorsal musculature, sexed, measured for length (tip of snout to fork of tail) and then immediately released into a large enclosure $(12.6 \mathrm{~m} \times 3.5 \mathrm{~m})$ constructed within the channel. The stocking schedule mimicked an arrival schedule, with a midseason peak. Daily observations were then used to determine the location, breeding behavior, and date and cause of death for each individual. All live fish could be detected within the enclosure every day. The above tagging, measurement, and observation procedures are standard and do not influence survival or reproductive behavior (e.g., Foote 1990; McPhee and Quinn 1998; Hendry et al. 1999).

In order to describe the functional form of age-specific mortality, it is first necessary to specify a starting time for the estimation of mortality. This is an important decision because different choices can bias the selection of the bestfitting function and the calculation of its coefficients (Allison 1995). Often, the age (in years) of first reproduction is used as the starting time in theoretical studies because this is when resources are first diverted away from survival and into reproduction (Kirkwood 1990; Kirkwood and Rose 1991; Abrams and Ludwig 1995; Williams and Day 2003). Following this lead, descriptive models of age-specific mortality in long-lived (multiple years), iteroparous species usually include a parameter specifying the age at which senescence starts, which may or may not be synchronous with the age of first maturity (e.g., Ricklefs 1998; Ricklefs and Scheuerlein 2001). Alternatively, studies of senescence in annual insects typically use the first day of the adult stage (e.g., Tatar and Carey 1995; Service et al. 1998; Bonduriansky and Brassil 2002; Fox et al. 2003) or the onset of egglaying or adult feeding (Boggs 1997b).

For Pacific salmon, the choice of a starting time for the estimation of age-specific mortality is not a trivial matter. For example, costly investment in gonads or secondary sexual characters commences weeks before the onset of breeding (Hendry and Berg 1999). Moreover, the onset of breeding may be only loosely connected to the onset of senescence-as would be the case for delayed effects on survival (Mangel 2001; Partridge and Gems 2002). Previously, we considered the most logical choice of a starting date to be the date of arrival at breeding areas (Hendry et al. 2004; Morbey and Abrams 2004). This event marks the time when maturing individuals are first exposed to the full suite of relevant mortality factors, including parasites, predators, adverse abiotic conditions, and costly mating behaviors. In Meadow Creek, however, some females arrive at breeding areas days to weeks before they start breeding (Morbey and Ydenberg 2003). In this study, we first estimate age-specific mortality relative to when individuals arrive at breeding areas (i.e., arrival date), but we also investigate how a delay in the onset of breeding can influence the estimation of mortality rates.

\section{Estimating Age-Specific Mortality}

We used maximum likelihood analysis to choose among survival models with different hazard functions (constant, Weibull, Gompertz, and Gompertz-logistic; table 1). Each of these models has a baseline hazard rate $(\beta)$ that is the logarithm of the instantaneous conditional mortality rate, that is, the number of deaths expected per capita conditional on survival to that time period. The Weibull, Gompertz, and Gompertz-logistic models have a rate parameter ( $\gamma$ for Weibull, $\alpha$ for Gompertz and Gompertz-logistic) that describes how hazard changes with time since arrival (note that the rate parameters cannot be directly compared among functional forms because of differing assumptions in the models). Senescence occurs when hazard increases with time since arrival. In addition to the rate parameter, the Gompertz-logistic model has a shape parameter $(\sigma)$ describing the heterogeneity among individuals with respect to their baseline hazard rate (Vaupel et al. 1979; Vaupel and Yashin 1985; Service 2000). The consequence of this heterogeneity is a plateau in the hazard function at old ages. Choosing among these distributions allows us to test for true senescence and provides the appropriate model to test for the effect of covariates (i.e., other intrinsic and extrinsic factors potentially influencing age-specific mortality). We note that the power to specify hazard rates at very young ages (i.e., shortly after arrival) is limited by the number of fish in the analysis. A detection threshold can be specified as $1 / n$, below which hazard rates cannot be readily interpreted (Promislow et al. 1999).

For both creeks, we collected data on a number of covariates that might affect senescence: year, sex, body length, and arrival date. For Pick Creek, an additional covariate was ocean age (number of years spent in the ocean). It is useful to narrow down the possible covariates for inclusion in the specific models because nonsignificant covariates can obscure the age-specific pattern of senescence. We first determined all significant covariates by fitting Cox proportional hazard $(\mathrm{PH})$ models implemented in PROC PHREG in SAS, version 8.02, which makes no assumptions

Table 1: Comparison of hazard functions for the four survival models tested

\begin{tabular}{ll}
\hline Survival model & Hazard function, $h(T)$ \\
\hline Constant & $\exp \beta$ \\
Weibull & $\exp [\beta+(\gamma-1) \ln T]$ \\
Gompertz & $\exp (\beta+\alpha T)$ \\
Gompertz-logistic & $\frac{\exp (\beta+\alpha T)}{1+\sigma^{2} \exp \beta[\exp (\alpha T)-1] / \alpha}$ \\
\hline
\end{tabular}


about the underlying distribution of survival times (i.e., Weibull or Gompertz; Allison 1995). Using the results of the $\mathrm{PH}$ analysis, models with specific functional forms were constructed, and maximum likelihood estimates of parameters were found with the FindRoot function in Mathematica 5.0 (Wolfram Research 2003). Instantaneous hazard functions were integrated from time $T-1$ to $T$ in order to generate daily probabilities of mortality, and individual mortality data were assumed to have a binomial distribution. Increasingly complex models were formulated and compared across functional forms. When additional complexity did not yield a better model, the support for each covariate was tested by eliminating it from the model.

Model selection was based on Akaike's Information Criterion (AIC), which is a standard method of choosing among models that uses the negative log likelihood and the number of fit parameters for the best-fit model. While it has often been interpreted as trading model fit for model complexity, it is best interpreted as arising from fundamental statistical theory (Burnham and Anderson 2002). We also report the evidence ratio, which is the odds ratio of support for the best-fit model over the listed model. The best-fit model, by definition, is the most supported. However, a model with an evidence ratio of $<3$ still has substantial support, whereas an evidence ratio $>150$ indicates almost no support (Burnham and Anderson 2002). Confidence intervals for parameters in the best-fit model were generated by examining the likelihood profile (Venzon and Moolgavkar 1988). Analysis was first conducted by examining a single functional form across all four years represented in the two populations. This aided in comparison of parameters with similar meanings in all years. There was sufficient support for year-specific parameters that subsequent analyses fitted entirely separate models to each year.

The Pick Creek data were collected over two years (1995 and 1996) and included individuals that were known to have died of senescence $(n=273)$, were known to have been killed by gulls or bears $(n=75)$, disappeared without determination of the cause of death $(n=226)$, or were alive at the experiment's end $(n=24)$. The Meadow Creek data were collected over two years (1998 and 1999) and included only individuals that died of senescence (i.e., none were killed by predators). A total of 181 individuals died during the observation time, and nine individuals were still alive at the end of the experiment. Individuals that died of predation, died of unknown causes, or were alive at the end of the experiment were included as noninformative, rightcensored observations; in other words, they did not have traits that made them more likely to die of predation, disappear, or breed late in the season.

Predation is a common source of mortality on breeding adults in Pick Creek (Quinn et al. 2001a; Gende et al. 2004). In a second analysis, we therefore examined the functional form of age-specific mortality due to predation in Pick Creek and determined the significant covariates using PROC PHREG. In this analysis, individuals that died of senescence, died of unknown causes, or were alive at the end of the experiment were right censored.

Arrival date is the date of entry into the creek where spawning takes place and closely coincides with the onset of breeding in Pick Creek (Hendry et al. 1999). In Meadow Creek, some early-arriving females delay ovulation for several days after arrival and, as a consequence, similarly delay their nest settlement and territory defense (Morbey and Ydenberg 2003). We determined the effect of such a delay by first comparing hazard models with different starting times (arrival date, date of nest settlement, or calendar date) and then testing for an effect of wait duration in a hazard model based on arrival date. Unlike the previous analyses, these models considered only females that constructed and defended nests (73 uncensored and five rightcensored observations; 17 females were excluded because they never defended nests and died without spawning).

\section{Results}

The Gompertz-logistic model was the single best-fitting functional form across all four years, and year-specific parameters were important in the baseline parameter $(\beta)$, the rate parameter $(\alpha)$, and the shape parameter $(\sigma$; table 2 , model D). Consequently, each year was modeled separately. The best-fit model for Pick Creek in 1995 was a Gompertz model (fig. 1A). The best-fit model for Pick Creek in 1996 and for Meadow Creek in 1999 was a Gompertz-logistic model, in part because of a leveling off in the mortality rate at old ages (fig. 1B, 1D). The best-fit model for Meadow Creek in 1998 was a Weibull model because of an early rise in the hazard rate followed by a comparatively gradual increase in the hazard rate at older ages (fig. $1 C$ ). In all years, the hazard rate began very close to 0 and increased with time since arrival (i.e., true senescence). The 1998 season was the most distinct because of a much higher probability of mortality at young ages.

In addition to large annual variation in senescence, there was strong support for a positive effect of arrival date on hazard rate in each year (tables 3-6). Moreover, there was no evidence that the effect of arrival date differed among the four years (table 2; cf. models C and D). Arrival date was modeled as part of the baseline parameter in the hazard rate. Initial mortality rates were near 0 ; consequently, covariates in the baseline parameter could be interpreted as influencing the age of onset for senescence. Salmon with a later arrival date had higher mortality rates at young ages, which may reflect an earlier onset of senescence. 
Table 2: Comparison of models for the instantaneous hazard rate for senescent death, $h(T)$ : all four years

\begin{tabular}{|c|c|c|c|c|c|}
\hline Model & Major effects & $h(T)^{\mathrm{a}}$ & $n^{\mathrm{b}}$ & AIC & $\begin{array}{l}\text { Evidence } \\
\text { ratio }\end{array}$ \\
\hline \multicolumn{6}{|c|}{ Weibull: } \\
\hline A & & $\exp \left[\beta_{s}+\left(\gamma_{s}-1\right) \ln T+\varepsilon_{s} D\right]$ & 12 & $2,734.6$ & $>10^{10}$ \\
\hline \multicolumn{6}{|c|}{ Gompertz: } \\
\hline $\mathrm{B}$ & & $\exp \left(\beta_{s}+\alpha_{s} T+\varepsilon_{s} D\right)$ & 12 & $2,800.0$ & $>10^{10}$ \\
\hline \multicolumn{6}{|c|}{ Gompertz-logistic: } \\
\hline C & Arrival date, year & $\exp \left(\beta_{s}+\alpha_{s} T+\varepsilon_{s} D\right)$ & 16 & $2,696.0$ & 71 \\
\hline $\mathrm{D}$ & Remove year-specific $\varepsilon$ & $\begin{array}{c}1+\sigma_{s}^{2} \exp \left(\beta_{s}+\varepsilon_{s} D\right)\left[\exp \left(\alpha_{s} T\right)-1\right] / \alpha_{s} \\
\exp \left(\beta_{s}+\alpha_{s} T+\varepsilon D\right) \\
\end{array}$ & 13 & $2,695.7$ & 61 \\
\hline \multirow[t]{2}{*}{$\mathrm{E}$} & Remove year-specific shape & $\begin{array}{c}1+\sigma_{s}^{2} \exp \left(\beta_{s}+\varepsilon D\right)\left[\exp \left(\alpha_{s} T\right)-1\right] / \alpha_{s} \\
\exp \left(\beta_{s}+\alpha_{s} T+\varepsilon D\right) \\
\end{array}$ & 10 & $2,723.0$ & $>10^{5}$ \\
\hline & parameter $\sigma$ & $1+\sigma^{2} \exp \left(\beta_{s}+\varepsilon D\right)\left[\exp \left(\alpha_{s} T\right)-1\right] / \alpha_{s}$ & & & \\
\hline \multirow[t]{2}{*}{$\mathrm{F}$} & Remove year-specific rate $\alpha$ & $\exp \left(\beta_{s}+\alpha T+\varepsilon D\right)$ & 10 & $2,809.7$ & $>10^{10}$ \\
\hline & & $1+\sigma_{s}^{2} \exp \left(\beta_{s}+\varepsilon D\right)[\exp (\alpha T)-1] / \alpha$ & & & \\
\hline \multirow[t]{2}{*}{ G } & Remove year-specific baseline $\beta$ & $\exp \left(\beta+\alpha_{s} T+\varepsilon D\right)$ & 10 & $3,244.4$ & $>10^{10}$ \\
\hline & & $1+\sigma_{s}^{2} \exp (\beta+\varepsilon D)\left[\exp \left(\alpha_{s} T\right)-1\right] / \alpha_{s}$ & & & \\
\hline \multicolumn{6}{|c|}{ Mixed distributions: } \\
\hline $\mathrm{H}^{\mathrm{c}}$ & & See tables 3-6 & 14 & $2,687.4$ & 1 \\
\hline
\end{tabular}

However, because of the detection threshold in these data, it is difficult to differentiate between extremely low rates of senescent mortality and a delayed onset of senescent mortality.

For the subset of Meadow Creek females that constructed and defended nests, a senescence model in which age is measured as time since arrival at the creek $(\mathrm{AIC}=733)$ was better than a model based on date of nest settlement $(\mathrm{AIC}=775)$ or calendar date $(\mathrm{AIC}=$ 771). This comparison was based on a Weibull model with year-specific parameters for baseline and rate and yearspecific parameters for the covariate arrival date. However, wait duration was an important negative covariate affecting the baseline hazard in a model of senescence based on time since arrival (AIC $=615$ with wait duration vs. $\mathrm{AIC}=733$ without wait duration). Females that waited longer to defend nests appeared to have a delayed onset of senescence, although it is also possible that they had lower rates of senescent mortality.

Predation mortality was slightly higher than 0 at arrival and steadily increased thereafter (fig. 2). The best-fit functional form for predation was a Gompertz model with year and sex affecting the baseline and rate parameters and the inclusion of body length as a significant covariate (table 7, model E). The hazard for predation was higher in 1995 than in 1996 (fig. 2), higher in males than in females, and higher among smaller individuals. Although model E sug- gests that the effect of body length was more pronounced among females than males, a similar model without this sex difference could not be strongly rejected (model F; evidence ratio $=4.3$ ). Moreover, there was only moderate support for a difference in the effect of body length between the sexes (model I). Overall, there was very strong support for a separate baseline parameter in each year (model $\mathrm{H}$ ) and for the inclusion of body length (model $J)$. There was moderate support for the sexes having separate baseline (model $\mathrm{G}$ ) and rate (model L) parameters.

\section{Discussion}

Pacific salmon clearly show true senescence, manifested as an increasing risk of mortality due to senescence (i.e., intrinsic mortality) with increasing time since arrival at breeding areas (see also Hendry et al. 2004; Morbey and Abrams 2004). Annual and seasonal variation in senescence was large and appeared to be manifest primarily as variation in the onset of senescence rather than in its rate after onset (fig. 1; fig. 4 of Hendry et al. 2004; fig. 3 of Morbey and Abrams 2004). This suggests that salmon accumulate damage to their soma until a threshold has been reached, after which senescence proceeds at a rapid and accelerating rate. The selection of different functional forms in each year further emphasizes the large annual variation in senescence but should not be interpreted as 

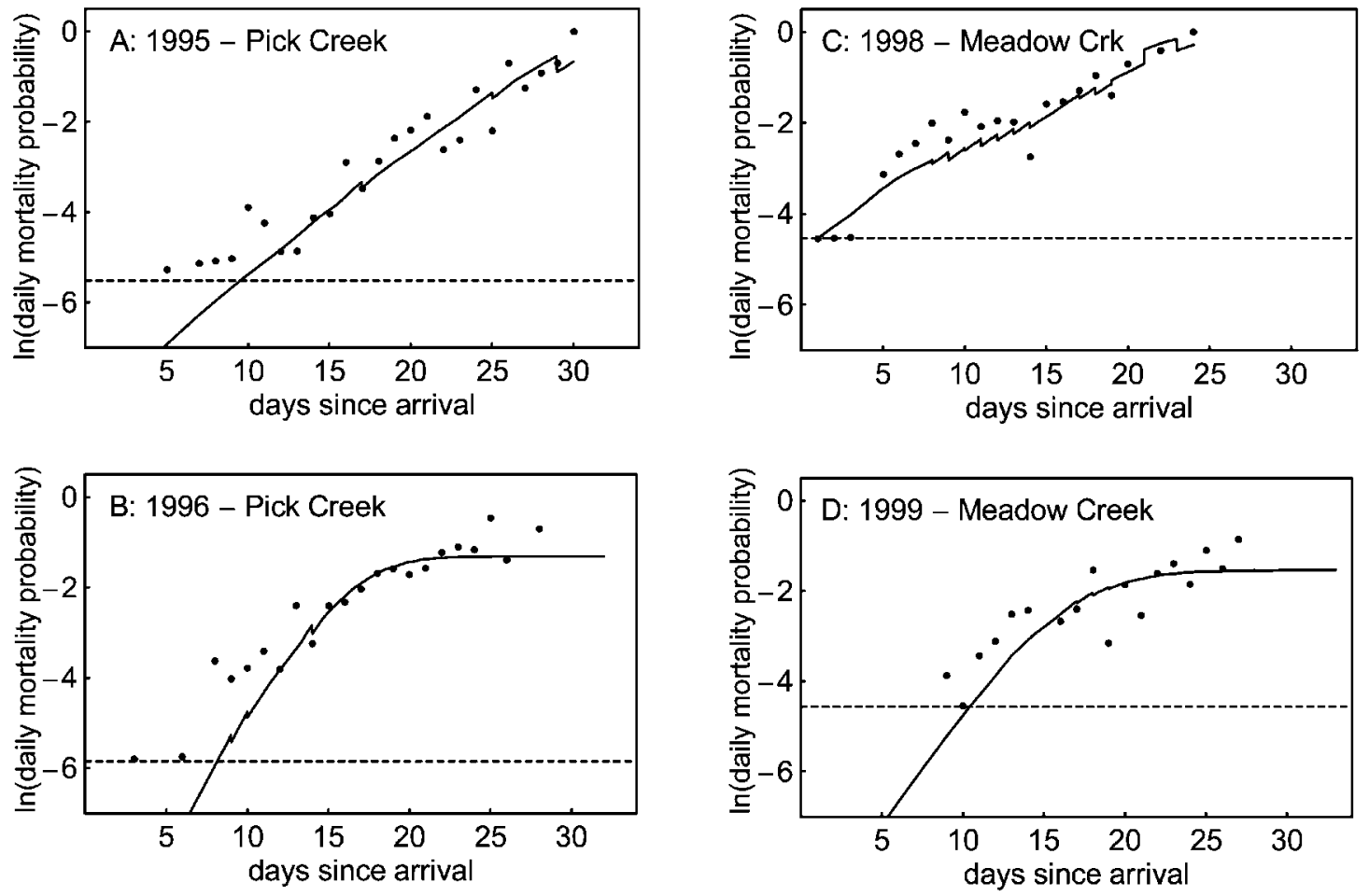

Figure 1: Daily mortality probability, excluding mortality due to predation, in Pick Creek $(A, B)$ and Meadow Creek $(C, D)$. The dots are based on the data, and the solid line is based on the best-fit model for each year (tables 3-6). Zero values for the observed data are not plotted, but the solid line extends only across the range of days for which observations exist for each year. The solid line is jagged because arrival date in the hazard function is based on the average arrival date of the fish alive at each given age. The dashed line represents the detection threshold below which hazard rates cannot be readily interpreted because of a lack of power.

evidence of fundamentally different mechanisms of senescence. It is possible that a single functional form would sufficiently describe all years, given larger sample sizes.

\section{Variation within Populations}

One line of evidence supporting possible nonadaptive environmental influences on senescence comes from interannual variation, particularly in Meadow Creek. In this population, age-specific hazard was much lower in 1999, when water temperatures were cooler and the intensity of fungal infection and prevalence of leeches on the kokanee were lower (see also Morbey and Ydenberg 2003). Low temperatures may delay senescence by slowing metabolism or other physiological processes controlling senescence, whereas low parasite loads may reduce the need for a costly immune response and may lower the direct risk of mortality. In Pick Creek, senescence also differed between years, but interannual differences in abiotic conditions were not evident. Although the younger average ocean age and smaller size of Pick Creek salmon in 1996 (Hendry et al. 1999) might have factored into their earlier onset of senescence because of lower energy reserves, neither of these traits statistically influenced senescence within years.

The nearly ubiquitous seasonal decline in reproductive life span within Pacific salmon populations (Neilson and Geen 1981; Neilson and Banford 1983; Perrin and Irvine 1990; McPhee and Quinn 1998; Hendry et al. 1999, 2004; Dickerson et al. 2002; Morbey and Ydenberg 2003; Morbey and Abrams 2004; but see van den Berghe and Gross 1986) is consistent with adaptive variation. Based on verbal arguments and explicit game-theoretical models with empirically supported assumptions, this seasonal pattern can be explained as an adaptation related to competition for nesting space among females and to competition for mates among males. For females, selection favors long life in early breeders so that they can prevent late breeders from digging their nests in the same location, which would cause severe mortality of incubating eggs. For males, selection favors long life in early breeders so that they can court more females. These selective pressures do not, however, favor long life in late-breeding females (because few females will arrive later to threaten their nests) or late-breeding males (because few additional females will become available). 
Table 3: Comparison of models for the instantaneous hazard rate for senescent death, $h(T)$ : Pick Creek, 1995

\begin{tabular}{|c|c|c|c|c|c|}
\hline Model & Major effects & $h(T)^{\mathrm{a}}$ & $n^{\mathrm{b}}$ & AIC & Evidence ratio \\
\hline \multicolumn{6}{|c|}{ Constant: } \\
\hline A & & $\exp \beta$ & 1 & 747.5 & $>10^{10}$ \\
\hline \multicolumn{6}{|c|}{ Weibull: } \\
\hline $\mathrm{B}$ & & $\exp [\beta+(\gamma-1) \ln T]$ & 2 & 565.0 & $>10^{10}$ \\
\hline $\mathrm{C}$ & Arrival date & $\exp [\beta+(\gamma-1) \ln T+\varepsilon D]$ & 3 & 517.4 & 209 \\
\hline \multicolumn{6}{|c|}{ Gompertz: } \\
\hline $\mathrm{D}$ & & $\exp (\beta+\alpha T)$ & 2 & 560.7 & $>10^{10}$ \\
\hline $\mathrm{E}^{\mathrm{c}}$ & Arrival date & $\exp (\beta+\alpha T+\varepsilon D)$ & 3 & 506.7 & 1 \\
\hline \multicolumn{6}{|c|}{ Gompertz-logistic: } \\
\hline $\mathrm{F}$ & & $\exp (\beta+\alpha T)$ & 3 & 562.7 & $>10^{10}$ \\
\hline \multirow{3}{*}{ G } & \multirow{3}{*}{ Arrival date } & $\overline{1+\sigma^{2} \exp \beta[\exp (\alpha T)-1] / \alpha}$ & & & \\
\hline & & $\exp (\beta+\alpha T+\varepsilon D)$ & 4 & 508.7 & 2.72 \\
\hline & & $\overline{1+\sigma^{2} \exp (\beta+\varepsilon D)[\exp (\alpha T)-1] / \alpha}$ & & & \\
\hline
\end{tabular}

a $T=$ time (days); $D=$ arrival date. The percent change in hazard for a unit increase in arrival date is $(1-\exp \varepsilon) \times 100$.

b Number of parameters for each model.

c The best-fitting, most parsimonious model. Estimated parameters and 95\% confidence intervals are $\beta=-9.7(-11.0,-8.5) ; \gamma=0.32(0.27,0.37)$; $\varepsilon=0.22(0.16,0.27)$.

Faced with relaxed selection to delay senescence, late breeders evolve shorter reproductive life spans because they do not need to reserve as much energy for metabolism and can invest more in other components of fitness, such as egg production (females) or secondary sexual traits (males; Hendry et al. 1999, 2001, 2004; Morbey and Ydenberg 2003; Morbey and Abrams 2004). While alternative nonadaptive hypotheses may still exist, none of them have the degree of empirical or theoretical support of the above adaptive hypotheses. Because much of the empirical support for these hypotheses comes from two populations (Pick Creek sockeye salmon and Meadow Creek kokanee), a logical next step is to test the underlying assumptions and predictions in different systems.

In addition to environmental effects and adaptation, senescence may be influenced by reproductive behaviors of the individuals themselves, particularly through direct insults on the soma (Tatar and Carey 1995; Partridge 2001). For females, considerable energy is expended aggressively defending their nest sites from the intrusions of other females (Schroder 1981; van den Berghe and Gross 1986, 1989; Foote 1990). Because survival depends on somatic reserves, these energetically costly activities should reduce future survival. This likely explains why postarrival

Table 4: Comparison of models for the instantaneous hazard rate for senescent death, $h(T)$ : Pick Creek, 1996

\begin{tabular}{|c|c|c|c|c|c|}
\hline Model & Major effects & $h(T)^{\mathrm{a}}$ & $n^{\mathrm{b}}$ & AIC & Evidence ratio \\
\hline \multicolumn{6}{|c|}{ Constant: } \\
\hline A & & $\exp \beta$ & 1 & $1,618.6$ & $>10^{10}$ \\
\hline \multicolumn{6}{|l|}{ Weibull: } \\
\hline $\mathrm{B}$ & & $\exp [\beta+(\gamma-1) \ln T]$ & 2 & $1,241.1$ & $>10^{10}$ \\
\hline $\mathrm{C}$ & Arrival date & $\exp [\beta+(\gamma-1) \ln T+\varepsilon D]$ & 3 & $1,164.1$ & $>10^{7}$ \\
\hline \multicolumn{6}{|c|}{ Gompertz: } \\
\hline $\mathrm{D}$ & & $\exp (\beta+\alpha T)$ & 2 & $1,271.0$ & $>10^{10}$ \\
\hline $\mathrm{E}$ & Arrival date & $\exp (\beta+\alpha T+\varepsilon D)$ & 3 & $1,213.1$ & $>10^{10}$ \\
\hline \multicolumn{6}{|c|}{ Gompertz-logistic: } \\
\hline $\mathrm{F}$ & & $\exp (\beta+\alpha T)$ & 3 & $1,242.8$ & $>10^{10}$ \\
\hline \multirow[t]{2}{*}{$\mathrm{G}^{\mathrm{c}}$} & \multirow[t]{2}{*}{ Arrival date } & $\begin{array}{c}1+\sigma^{2} \exp \beta[\exp (\alpha T)-1] / \alpha \\
\exp (\beta+\alpha T+\varepsilon D)\end{array}$ & 4 & $1,130.8$ & 1 \\
\hline & & $\overline{1+\sigma^{2} \exp (\beta+\varepsilon D)[\exp (\alpha T)-1] / \alpha}$ & & & \\
\hline
\end{tabular}

a $T=$ time (days); $D=$ arrival date. The percent change in hazard for a unit increase in arrival date is $(1-\exp \varepsilon) \times 100$.

b Number of parameters for each model.

c The best-fitting, most parsimonious model. Estimated parameters and 95\% confidence intervals are $\beta=-13(-16,-11) ; \alpha=0.7(0.5,0.9) ; \sigma=1.5$ (1.1, 1.9); $\varepsilon=0.22(0.16,0.29)$. 
Table 5: Comparison of models for the instantaneous hazard rate for senescent death, $h(T)$ : Meadow Creek, 1998

\begin{tabular}{|c|c|c|c|c|c|}
\hline Model & Major effects & $h(T)^{\mathrm{a}}$ & $n^{\mathrm{b}}$ & $\mathrm{AIC}$ & Evidence ratio \\
\hline \multicolumn{6}{|c|}{ Constant: } \\
\hline A & & $\exp \beta$ & 1 & 641.8 & $>10^{10}$ \\
\hline \multicolumn{6}{|c|}{ Weibull: } \\
\hline B & & $\exp [\beta+(\gamma-1) \ln T]$ & 2 & 565.1 & $>10^{10}$ \\
\hline $\mathrm{C}^{\mathrm{c}}$ & Arrival date & $\exp [\beta+(\gamma-1) \ln T+\varepsilon D]$ & 3 & 504.5 & 1 \\
\hline \multicolumn{6}{|c|}{ Gompertz: } \\
\hline $\mathrm{D}$ & & $\exp (\beta+\alpha T)$ & 2 & 571.1 & $>10^{10}$ \\
\hline $\mathrm{E}$ & Arrival date & $\exp (\beta+\alpha T+\varepsilon D)$ & 3 & 514.7 & 159 \\
\hline \multicolumn{6}{|c|}{ Gompertz-logistic: } \\
\hline \multirow[t]{2}{*}{$\mathrm{F}$} & & $\exp (\beta+\alpha T)$ & 3 & 573.1 & $>10^{10}$ \\
\hline & Arrival date & $\begin{array}{c}\overline{1+\sigma^{2} \exp \beta[\exp (\alpha T)-1] / \alpha} \\
\exp (\beta+\alpha T+\varepsilon D)\end{array}$ & 4 & 511.9 & 36 \\
\hline G & & $\overline{1+\sigma^{2} \exp (\beta+\varepsilon D)[\exp (\alpha T)-1] / \alpha}$ & & & \\
\hline
\end{tabular}

a $T=$ time (days); $D=$ arrival date. The percent change in hazard for a unit increase in arrival date is $(1-\exp \varepsilon) \times 100$.

b Number of parameters for each model.

${ }^{c}$ The best-fitting, most parsimonious model. Estimated parameters and 95\% confidence intervals are $\beta=-10.5(-12.5,-8.6)$; $\gamma=3.6(3.1,4.3)$; $\varepsilon=0.28(0.20,0.35)$.

waiting appeared to delay the onset of senescence (see also Morbey and Ydenberg 2003). For males, considerable energy is expended during fights with other males and displays to males and females (e.g., Quinn and Foote 1994; Quinn et al. 1996; Healey et al. 2003). Consequently, higher levels of reproductive competition reduced reproductive life span for males in Pick Creek (Hendry et al. 2001). In short, the onset of senescence is not perfectly synchronized to a particular life-history event but is also modulated by reproductive activities.

Given the amount of unexplained variation among years that we observed in senescence, controlled experiments at natural breeding areas may help to determine the relative importance of different environmental factors directly affecting senescence (e.g., temperature, parasites). Moreover, the finding of a Gompertz-logistic model in two of the years suggests that other important covariates need to be considered. It may also be possible to determine whether increased accumulation of resources in the ocean (by individuals within years or by cohorts in different years) allows increased allocation to survival without compromising investment in gonads (or vice versa).

\section{Variation between Populations}

Pick Creek sockeye salmon and Meadow Creek kokanee have very different natural histories. Pick Creek sockeye

Table 6: Comparison of models for the instantaneous hazard rate for senescent death, $h(T)$ : Meadow Creek, 1999

\begin{tabular}{|c|c|c|c|c|c|}
\hline Model & Major effects & $h(T)^{\mathrm{a}}$ & $n^{\mathrm{b}}$ & AIC & Evidence ratio \\
\hline \multicolumn{6}{|c|}{ Constant: } \\
\hline A & & $\exp \beta$ & 1 & 701.9 & $>10^{10}$ \\
\hline \multicolumn{6}{|c|}{ Weibull: } \\
\hline $\mathrm{B}$ & & $\exp [\beta+(\gamma-1) \ln T]$ & 2 & 571.9 & $>10^{5}$ \\
\hline $\mathrm{C}$ & Arrival date & $\exp [\beta+(\gamma-1) \ln T+\varepsilon D]$ & 3 & 548.7 & 4.95 \\
\hline \multicolumn{6}{|c|}{ Gompertz: } \\
\hline $\mathrm{D}$ & & $\exp (\beta+\alpha T)$ & 2 & 589.8 & $>10^{9}$ \\
\hline $\mathrm{E}$ & Arrival date & $\exp (\beta+\alpha T+\varepsilon D)$ & 3 & 565.6 & $>10^{4}$ \\
\hline \multicolumn{6}{|c|}{ Gompertz-logistic: } \\
\hline $\mathrm{F}$ & & $\exp (\beta+\alpha T)$ & 3 & 571.6 & $>10^{5}$ \\
\hline \multirow[t]{2}{*}{$\mathrm{G}^{\mathrm{c}}$} & \multirow[t]{2}{*}{ Arrival date } & $\begin{array}{r}1+\sigma^{2} \exp \beta[\exp (\alpha T)-1] / \alpha \\
\exp (\beta+\alpha T+\varepsilon D) \\
\end{array}$ & 4 & 545.5 & 1 \\
\hline & & $\overline{1+\sigma^{2} \exp (\beta+\varepsilon D)[\exp (\alpha T)-1] / \alpha}$ & & & \\
\hline
\end{tabular}



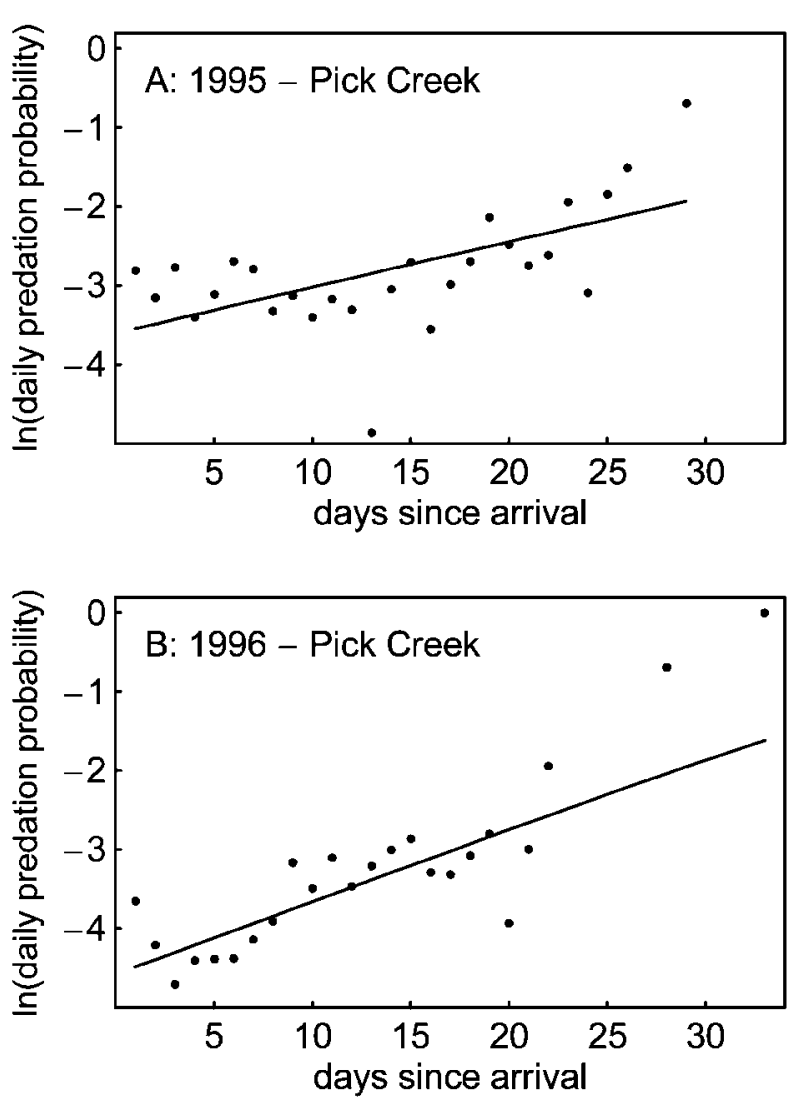

Figure 2: Predation mortality in Pick Creek in $1995(A)$ and 1996 (B). The dots are based on the data, and the solid line is based on the bestfit model (table 7). Zero values for the observed data are not plotted, but the solid line extends only across the range of days for which observations exist for each year. The solid line is based on the average length of fish in each year and assumes an equal mixture of males and females.

salmon are large $(388-564 \mathrm{~mm})$ and anadromous, with long oceanic migrations, substantial predation risk at breeding areas, and no postarrival waiting (Quinn et al. 2001a; Gende et al. 2004). Meadow Creek kokanee are small (192-234 mm) and nonanadromous, with a short migration, low predation risk at breeding areas, and substantial postarrival waiting. Despite these differences, patterns of senescence did not show consistent differences between Pick Creek and Meadow Creek (fig. 1). The onset of senescence was not earlier in Pick Creek, the seasonal increase in hazard was statistically similar in all four years, and neither sex nor body size affected senescence within either population. These similarities suggest that selection acts on intrinsic survival mechanisms in a similar way across populations and sexes, generally favoring a seasonal decline in life span.

At face value, we might conclude that the lack of clear differences between populations counters evolutionary predictions about the role of extrinsic mortality (Medawar 1952; Williams 1957; Kirkwood 1990; Kirkwood and Rose 1991; Morbey and Ydenberg 2003; Morbey and Abrams 2004), which is clearly much higher in Pick Creek. This might not be true, however, because annual variation in senescence caused by environmental influences might have obscured a population difference in intrinsic survival mechanisms. Moreover, the Meadow Creek spawning channel is a man-made environment, and the population may have evolved previously under a different suite of extrinsic mortality factors. On the other hand, recent theoretical work suggests that if individuals in poorer condition are more vulnerable to predation, a higher predation environment may select against physiological deterioration and favor delayed senescence (Williams and Day 2003). This argument was used to explain why guppies from a high-predation environment showed slower senescence (Reznick et al. 2004). Although our results also do not support this prediction (because senescent mortality rates were not lower in Pick Creek than in Meadow Creek), the observed age-specific increase in predation hazard among Pick Creek salmon suggests that condition-dependent predation risk may play a role in affecting patterns of senescence.

\section{Senescence in Reproductive Rate and Predator Avoidance}

In Pacific salmon, senescence in survival is now well established, but senescence in reproductive rate remains uncertain. For males, breeders in some populations appear to weaken with age and may lose their ability to monopolize females (Quinn and Foote 1994; Quinn et al. 1996). This interpretation is subject to question, however, because observation studies often confound the effects of time since arrival, female availability, and competitor density. In contrast, controlled experiments in Meadow Creek revealed that males were not less likely to monopolize females in the days preceding death, at least after statistically controlling for female availability and competitor density (Morbey 2002). Males can also acquire a prior-resident advantage (Foote 1990; Chebanov 1997; Morbey 2003), potentially counteracting reproductive senescence.

Although rates of aggression during nest defense decline in the days preceding death, female sockeye salmon are rarely usurped by other females (Quinn and McPhee 1998). Similarly, female kokanee in Meadow Creek were able to defend their nests until 1-2 days before death and were rarely displaced (Foote 1990; Y. E. Morbey, unpublished data). Furthermore, competitor density does not appear to influence female reproductive life span, suggesting that females are effective at nest defense under a wide variety of conditions (Quinn and McPhee 1998; Hen- 
Table 7: Comparison of models for the instantaneous hazard rate for predation death, $h(T)$ : Pick Creek

\begin{tabular}{|c|c|c|c|c|c|}
\hline Model & Major effect & $h(T)^{\mathrm{a}}$ & $n^{\mathrm{b}}$ & AIC & $\begin{array}{l}\text { Evidence } \\
\text { ratio }\end{array}$ \\
\hline \multicolumn{6}{|l|}{$\begin{array}{l}\text { Comparison of functional } \\
\text { forms: }\end{array}$} \\
\hline A: constant & & $\exp \beta$ & 1 & $2,550.1$ & $>10^{10}$ \\
\hline B: Weibull & & $\exp [\beta+(\gamma-1) \ln T]$ & 2 & $3,142.8$ & $>10^{10}$ \\
\hline C: Gompertz-logistic & & $\exp (\beta+\alpha T)$ & 3 & $2,525.3$ & $>10^{10}$ \\
\hline D: Gompertz & & $\begin{array}{l}\overline{1+\sigma^{2} \exp \beta[\exp (\alpha T)-1] / \alpha} \\
\exp (\beta+\alpha T)\end{array}$ & 2 & $2,523.3$ & $>10^{10}$ \\
\hline \multicolumn{6}{|l|}{ Gompertz best-fit models: } \\
\hline $\mathrm{E}^{\mathrm{c}}$ & Length $\times$ gender & $\exp \left(\beta_{s, g}+\lambda_{g} L+\alpha_{s, g} T\right)$ & 10 & $2,380.6$ & 1 \\
\hline $\mathrm{F}$ & Length $\times$ year & $\exp \left(\beta_{s, g}+\lambda_{s} L+\alpha_{s, g} T\right)$ & 10 & $2,383.5$ & 4.3 \\
\hline \multicolumn{6}{|l|}{$\begin{array}{l}\text { Test each effect in best-fit } \\
\text { model: }\end{array}$} \\
\hline G & Remove gender from baseline & $\exp \left(\beta_{s}+\lambda_{g} L+\alpha_{s, g} T\right)$ & 8 & $2,386.2$ & 16.7 \\
\hline $\mathrm{H}$ & Remove year from baseline & $\exp \left(\beta_{g}+\lambda_{g} L+\alpha_{s, g} T\right)$ & 8 & $2,409.2$ & $>10^{6}$ \\
\hline I & Remove length $\times$ gender & $\exp \left(\beta_{s, g}^{\delta}+\lambda L+\alpha_{s, g}^{\delta} T\right)$ & 9 & $2,384.4$ & 6.9 \\
\hline $\mathrm{J}$ & Remove length & $\exp \left(\beta_{s, g}+\alpha_{s, g} T\right)$ & 8 & $2,390.2$ & 125 \\
\hline $\mathrm{K}$ & Remove year from rate & $\exp \left(\beta_{s, g}+\lambda_{g} L+\alpha_{g} T\right)$ & 8 & $2,381.4$ & 1.5 \\
\hline $\mathrm{L}$ & Remove gender from rate & $\exp \left(\beta_{s, g}+\lambda_{g} L+\alpha_{s} T\right)$ & 8 & $2,384.0$ & 5.7 \\
\hline M & Remove gender $\times$ year from rate & $\exp \left(\beta_{s, g}+\lambda_{g} L+\alpha T\right)$ & 7 & $2,384.5$ & 7.1 \\
\hline
\end{tabular}

dry et al. 2001; Morbey and Ydenberg 2003). This apparent lack of evidence for gradual reproductive senescence may reflect a physiological ability to maintain a high reproductive rate despite high levels of environmental and social stress (Wingfield and Sapolsky 2003). From an evolutionary point of view, selection against reproductive senescence may be so high that it is never observed in natural salmon populations.

Predation rate increased with time since arrival for sockeye salmon in Pick Creek, which suggests that senescence and the accompanying loss of vigor increase an individual's vulnerability to bears (see also Gende et al. 2004). This may be a typical pattern, particularly where environmental conditions allow younger, more vigorous salmon to evade bears by lateral escape into deeper water or under shelter (Gende et al. 2004). However, predation rate among females was lower and less dependent on age in one year but more dependent on age in another year. These results suggest that vulnerability to predators can be affected by senescent decline but not necessarily in all individuals.

Extrinsic and intrinsic factors also directly influenced an individual's vulnerability to predation in Pick Creek. Predation rates were higher in 1995 than in 1996, higher in males than in females, and higher among smaller individuals. Previous work on the same population yielded similar conclusions with respect to year and sex but did not find evidence of size-selective mortality (Quinn et al. 2001a). Moreover, in other species and populations, sizeselective predation appears to be relatively common but with larger individuals being more vulnerable (Quinn and Kinnison 1999; Ruggerone et al. 2000; Quinn et al. 2001a; Gende et al. 2004). Quinn et al. (2001b) suggested that the relatively deep water of Pick Creek makes it difficult for bears to selectively forage on larger individuals. Possibly, smaller females are more vulnerable to bears because they typically nest in shallower water (Hendry et al. 2001).

\section{Prospects}

Pacific salmon are an excellent system for continued research on senescence because much is already known about their physiology, ecology, and life history. We foresee several profitable lines of investigation. First, new research should focus on the physiological mechanisms underlying the trade-off between reproductive effort and senescence. Senescent mortality is thought to be an indirect consequence of adaptive resource allocation decisions, and understanding the mechanisms underlying this trade-off can be helpful in predicting optimal mortality trajectories (e.g., Mangel 2001; Mangel and Bonsall 2004). Second, it should 
be possible to relate age-specific intrinsic mortality to rates of extrinsic mortality, particularly because populations vary greatly in the intensity of bear predation (Quinn et al. 2001 $a, 2001 b$; Gende et al. 2004) and water temperature (Hodgson and Quinn 2002). These sorts of comparison would provide an excellent test of an important prediction of evolutionary theories of senescence, akin to tests provided with much lower potential replication in other taxa (e.g., Austad 1993; Bryant and Reznick 2004; Reznick et al. 2004). Third, given adaptive targets for senescence, it would be interesting to test for physiological adjustments (e.g., in resting or field metabolic rate) that compensate for ambient environmental conditions such as water temperature. Fourth, it would be useful to determine the genetic basis of variation in senescence. As a start, senescence could be quantified by rearing populations with different patterns of natural senescence in a common environment.

\section{Acknowledgments}

The inspiration for this article came from discussions with P. Abrams and D. Reznick about the difficulties of detecting senescence in nature when predation rates are very high. For logistical support in British Columbia, we thank the British Columbia Ministry of Water, Land, and Air Protection (formerly the Ministry of Environment), J. Bell, J. Hammond, J. MacDonald, M. Pearson, and T. Smith. For logistical support in Alaska, we thank O. Berg, M. Hendry, B. Lewis, T. Quinn, and personnel of the Fisheries Research Institute. For financial support, we thank the Garfield Weston Foundation and B. C. Packers, Simon Fraser University, and Natural Sciences and Engineering Research Council of Canada Discovery Grants to P. Abrams and A.P.H. This is Kellogg Biological Station contribution 1181 .

\section{Literature Cited}

Abrams, P. A. 1993. Does increased mortality favor the evolution of more rapid senescence? Evolution 47:877-887.

Abrams, P. A., and D. Ludwig. 1995. Optimality theory, Gompertz' Law, and the disposable soma theory of senescence. Evolution 49: 1055-1066.

Allison, P. D. 1995. Survival analysis using the SAS system: a practical guide. SAS Institute, Cary, NC.

Austad, S. N. 1993. Retarded senescence in an insular population of Virginia opossums (Didelphis virginiana). Journal of Zoology (London) 229:695-708.

Barry, T. P., M. J. Unwin, J. A. Malison, and T. P. Quinn. 2001. Free and total cortisol levels in semelparous and iteroparous chinook salmon. Journal of Fish Biology 59:1673-1676.

Boggs, C. L. 1997a. Dynamics of reproductive allocation from juvenile and adult feeding: radiotracer studies. Ecology 78:192-202.

- 1997b. Reproductive allocation from reserves and income in butterfly species with differing adult diets. Ecology 78:181-191.
Bonduriansky, R., and C. E. Brassil. 2002. Rapid and costly ageing in wild male flies. Nature 420:377.

. 2005. Reproductive ageing and sexual selection on male body size in a wild population of antler flies (Protopiophila litigata). Journal of Evolutionary Biology (forthcoming).

Brett, J. R. 1995. Energetics. Pages 3-68 in C. Groot, L. Margolis, and W. C. Clarke, eds. Physiological ecology of Pacific salmon. University of British Columbia Press, Vancouver.

Bryant, M. J., and D. Reznick. 2004. Comparative studies of senescence in natural populations of guppies. American Naturalist 163: 55-68.

Burnham, K. P., and D. R. Anderson. 2002. Model selection and multimodel inference: a practical information-theoretic approach. Springer, New York.

Carranza, J., S. Alarcos, C. B. Sánchez-Prieto, J. Valencia, and C. Mateos. 2004. Disposable-soma senescence mediated by sexual selection in an ungulate. Nature 432:215-218.

Carruth, L. L., R. M. Dores, T. A. Maldonado, D. O. Norris, T. Ruth, and R. E. Jones. 2000. Elevation of plasma cortisol during the spawning migration of landlocked kokanee salmon (Oncorhynchus nerka kennerlyi). Comparative Biochemistry and Physiology C 127: 123-131.

Chebanov, N. A. 1997. Role of the "prior resident" effect in formation of the dominance-subordination relations and determination of the reproductive success values in Pacific salmons. Journal of Ichthyology 37:110-115.

Dickerson, B. R., T. P. Quinn, and M. F. Willson. 2002. Body size, arrival date, and reproductive success of pink salmon, Oncorhynchus gorbuscha. Ethology Ecology and Evolution 14:29-44.

Dickhoff, W. W. 1989. Salmonids and annual fishes: death after sex. Pages 253-266 in M. P. Schreibman and C. G. Scanes, eds. Development, maturation, and senescence of neuroendocrine systems: a comparative approach. Academic Press, San Diego, CA.

Dudycha, J. L., and A. J. Tessier. 1999. Natural genetic variation of life span, reproduction, and juvenile growth in Daphnia. Evolution 53:1744-1756.

Finch, C. E. 1990. Longevity, senescence, and the genome. University of Chicago Press, Chicago.

Foote, C. J. 1988. Male mate choice dependent on male size in salmon. Behaviour 106:63-80.

- 1990. An experimental comparison of male and female spawning territoriality in a Pacific salmon. Behaviour 115:283314.

Fox, C. W., L. Dublin, and S. J. Pollitt. 2003. Gender differences in lifespan and mortality rates in two seed beetle species. Functional Ecology 17:619-626.

Gende, S. M., T. P. Quinn, R. Hilborn, A. P. Hendry, and B. Dickerson. 2004. Brown bears selectively kill salmon with higher energy content but only in habitats that facilitate choice. Oikos 104:518-528.

Gilhousen, P. 1980. Energy sources and expenditures in Fraser River sockeye salmon during spawning migration. International Pacific Salmon Fisheries Commission Bulletin 23.

Golden, T. R., D. A. Hinerfeld, and S. Melov. 2002. Oxidative stress and aging: beyond correlation. Aging Cell 1:117-123.

Groot, C., and L. Margolis. 1991. Pacific salmon life histories. University of British Columbia Press, Vancouver.

Hamilton, W. D. 1966. The moulding of senescence by natural selection. Journal of Theoretical Biology 12:12-45.

Healey, M. C., R. Lake, and S. G. Hinch. 2003. Energy expenditures 
during reproduction by sockeye salmon (Oncorhynchus nerka). Behaviour 140:161-182.

Hendry, A. P., and O. K. Berg. 1999. Secondary sexual characters, energy use, senescence, and the cost of reproduction in sockeye salmon. Canadian Journal of Zoology 77:1663-1675.

Hendry, A. P., O. K. Berg, and T. P. Quinn. 1999. Condition dependence and adaptation-by-time: breeding date, life history, and energy allocation within a population of salmon. Oikos 85:499-514.

- 2001. Breeding location choice in salmon: causes (habitat, competition, body size, energy stores) and consequences (life span, energy stores). Oikos 93:407-418.

Hendry, A. P., Y. E. Morbey, O. K. Berg, and J. K. Wenburg. 2004. Adaptive variation in senescence: reproductive life span in a wild salmon population. Proceedings of the Royal Society of London B 271:259-266.

Hodgson, S., and T. P. Quinn. 2002. The timing of adult sockeye salmon migration into fresh water: adaptations by populations to prevailing thermal regimes. Canadian Journal of Zoology 80:542555.

Hughes, K. A., J. A. Alipaz, J. M. Drnevich, and R. M. Reynolds. 2002. A test of evolutionary theories of aging. Proceedings of the National Academy of Sciences of the USA 99:14286-14291.

Keller, L., and M. Genoud. 1997. Extraordinary lifespans in ants: a test of evolutionary theories of ageing. Nature 389:958-960.

Kirkwood, T. B. L. 1990. The disposable soma theory of aging. Pages 9-19 in D. E. Harrison, ed. Genetic effects on aging. Vol. 2. Telford, Caldwell, NJ.

Kirkwood, T. B. L., and M. R. Rose. 1991. Evolution of senescence: late survival sacrificed for reproduction. Philosophical Transactions of the Royal Society of London B 332:15-24.

Maldonado, T. A., R. E. Jones, and D. O. Norris. 2002. Intraneuronal amyloid precursor protein (APP) and appearance of extracellular $\beta$-amyloid peptide $(\mathrm{A} \beta)$ in the brain of aging kokanee salmon. Journal of Neurobiology 53:11-20.

Mangel, M. 2001. Complex adaptive systems, aging and longevity. Journal of Theoretical Biology 213:559-571.

Mangel, M., and M. B. Bonsall. 2004. The shape of things to come: using models with physiological structure to predict mortality trajectories. Theoretical Population Biology 65:353-359.

Mathisen, O. A. 1962. The effect of altered sex ratios on the spawning of red salmon. Pages 137-248 in T. S. Y. Koo, ed. Studies of Alaska red salmon. University of Washington, Seattle.

McPhee, M. V., and T. P. Quinn. 1998. Factors affecting the duration of nest defense and reproductive lifespan of female sockeye salmon, Oncorhynchus nerka. Environmental Biology of Fishes 51:369-375.

Medawar, P. B. 1952. An unsolved problem in biology. Lewis, London.

Mommsen, T. P., M. M. Vijayan, and T. W. Moon. 1999. Cortisol in teleosts: dynamics, mechanisms of action, and metabolic regulation. Reviews in Fish Biology and Fisheries 9:211-268.

Morbey, Y. E. 2002. The mate-guarding behaviour of male kokanee (Oncorhynchus nerka). Behaviour 139:507-528.

- 2003. Pair formation, pre-spawning waiting, and protandry in kokanee Oncorhynchus nerka. Behavioral Ecology and Sociobiology 54:127-135.

Morbey, Y. E., and P. A. Abrams. 2004. The interaction between reproductive lifespan and protandry in seasonal breeders. Journal of Evolutionary Biology 17:768-778.

Morbey, Y. E., and R. C. Ydenberg. 2003. Timing games in the reproductive phenology of female Pacific salmon (Oncorhynchus spp.). American Naturalist 161:284-298.
Neilson, J. D., and C. E. Banford. 1983. Chinook salmon (Oncorhynchus tshawytscha) spawner characteristics in relation to redd physical features. Canadian Journal of Zoology 61:1524-1531.

Neilson, J. D., and G. H. Geen. 1981. Enumeration of spawning salmon from spawner residence time and aerial counts. Transactions of the American Fisheries Society 110:554-556.

Partridge, L. 2001. Evolutionary theories of ageing applied to longlived organisms. Experimental Gerontology 36:641-650.

Partridge, L., and D. Gems. 2002. Mechanisms of ageing: public or private? Nature Reviews Genetics 3:165-175.

Perrin, C. J., and J. R. Irvine. 1990. A review of survey life estimates as they apply to the area-under-the-curve method for estimating the spawning escapement of Pacific salmon. Canadian Technical Report of Fisheries and Aquatic Sciences 1733.

Promislow, D. E. L. 1991. Senescence in natural populations of mammals: a comparative study. Evolution 45:1869-1887.

Promislow, D. E. L., M. Tatar, S. Pletcher, and J. R. Carey. 1999. Below-threshold mortality: implications for studies in evolution, ecology and demography. Journal of Evolutionary Biology 12:314328.

Quinn, T. P., and C. J. Foote. 1994. The effects of body size and sexual dimorphism on the reproductive behaviour of sockeye salmon, Oncorhynchus nerka. Animal Behaviour 48:751-761.

Quinn, T. P., and M. T. Kinnison. 1999. Size-selective and sex-selective predation by brown bears on sockeye salmon. Oecologia (Berlin) 121:273-282.

Quinn, T. P., and M. V. McPhee. 1998. Effects of senescence and density on the aggression of adult female sockeye salmon. Journal of Fish Biology 52:1295-1300.

Quinn, T. P., M. D. Adkison, and M. B. Ward. 1996. Behavioral tactics of male sockeye salmon (Oncorhynchus nerka) under varying operational sex ratios. Ethology 102:304-322.

Quinn, T. P., A. P. Hendry, and G. B. Buck. 2001a. Balancing natural and sexual selection in sockeye salmon: interactions between body size, reproductive opportunity and vulnerability to predation by bears. Evolutionary Ecology Research 3:917-937.

Quinn, T. P., L. Wetzel, S. Bishop, K. Overberg, and D. E. Rogers. $2001 \mathrm{~b}$. Influence of breeding habitat on bear predation and age at maturity and sexual dimorphism of sockeye salmon populations. Canadian Journal of Zoology 79:1782-1793.

Reznick, D., C. Ghalambor, and L. Nunney. 2002. The evolution of senescence in fish. Mechanisms of Ageing and Development 123: 773-789.

Reznick, D. N., M. J. Bryant, D. Roff, C. K. Ghalambor, and D. E. Ghalambor. 2004. Effect of extrinsic mortality on the evolution of senescence in guppies. Nature 431:1095-1099.

Ricklefs, R. E. 1998. Evolutionary theories of aging: confirmation of a fundamental prediction, with implications for the genetic basis and evolution of life span. American Naturalist 152:24-44.

Ricklefs, R. E., and A. Scheuerlein. 2001. Comparison of aging-related mortality among birds and mammals. Experimental Gerontology 36:845-857.

Roff, D. A. 1992. The evolution of life histories: theory and analysis. Chapman \& Hall, New York.

. 2002. Life history evolution. Sinauer, Sunderland, MA.

Rose, M. R. 1991. Evolutionary biology of aging. Oxford University Press, New York.

Ruggerone, G. T., R. Hanson, and D. E. Rogers. 2000. Selective predation by brown bears (Ursus arctos) foraging on spawning sockeye 
salmon (Oncorhynchus nerka). Canadian Journal of Zoology 78: 974-981.

Sawada, M., U. Sester, and J. C. Carlson. 1993. Changes in superoxide radical formation, lipid peroxidation, membrane fluidity and cathepsin B activity in aging and spawning male Chinook salmon (Oncorhynchus tschawytscha). Mechanisms of Ageing and Development 69:137-147.

Schroder, S. L. 1981. The role of sexual selection in determining overall mating patterns and mate choice in chum salmon. $\mathrm{PhD}$ diss. University of Washington, Seattle.

Service, P. M. 2000. Heterogeneity in individual mortality risk and its importance for evolutionary studies of senescence. American Naturalist 156:1-13.

Service, P. M., C. A. Michieli, and K. McGill. 1998. Experimental evolution of senescence: an analysis using a "heterogeneity" mortality model. Evolution 52:1844-1850.

Sohal, R. S., R. J. Mockett, and W. C. Orr. 2002. Mechanisms of aging: an appraisal of the oxidative stress hypothesis. Free Radical Biology and Medicine 33:575-586.

Stearns, S. C. 1992. The evolution of life histories. Oxford University Press, New York.

Stein-Behrens, B. A., and R. M. Sapolsky. 1992. Stress, glucocorticoids, and aging. Aging Clinical and Experimental Research 4:197210.

Tatar, M., and J. R. Carey. 1995. Nutrition mediates reproductive trade-offs with age-specific mortality in the beetle Callosobruchus maculatus. Ecology 76:2066-2073.

Tatar, M., D. W. Gray, and J. R. Carey. 1997. Altitudinal variation for senescence in Melanoplus grasshoppers. Oecologia (Berlin) 111: 357-364.

van den Berghe, E. P., and M. R. Gross. 1986. Length of breeding life of coho salmon (Oncorhynchus kisutch). Canadian Journal of Zoology 64:1482-1486.
1989. Natural selection resulting from female breeding competition in a Pacific salmon (coho: Oncorhynchus kisutch). Evolution 43:125-140.

Vaupel, J. W., and A. I. Yashin. 1985. The deviant dynamics of death in heterogeneous populations. Sociological Methodology 15:179211.

Vaupel, J. W., K. G. Manton, and E. Stallard. 1979. The impact of heterogeneity in individual frailty on the dynamics of mortality. Demography 16:439-454.

Venzon, D. J., and S. H. Moolgavkar. 1988. A method for computing profile-likelihood-based confidence intervals. Applied Statistics 37: 87-94.

Vernon, E. H. 1957. Morphometric comparison of three races of kokanee (Oncorhynchus nerka) within a large British Columbia lake. Journal of the Fisheries Research Board of Canada 14:573598.

Williams, G. C. 1957. Pleiotropy, natural selection and evolution of senescence. Evolution 11:398-411.

1966. Adaptation and natural selection: a critique of some current evolutionary thought. Princeton University Press, Princeton, NJ.

Williams, P. D., and T. Day. 2003. Antagonistic pleiotropy, mortality source interactions and the evolutionary theory of senescence. Evolution 57:1478-1488.

Wingfield, J. C., and R. M. Sapolsky. 2003. Reproduction and resistance to stress: when and how. Journal of Neuroendocrinology 15: 711-724.

Wolfram Research. 2003. Mathematica 5.0. Wolfram Research, Champaign, IL.
Associate Editor: Daniel E. L. Promislow Editor: Jonathan B. Losos 